\title{
HELICOBACTER INFECTION AND ALLERGY IN MAJORITY AND ROMA POPULATION IN THE CZECH REPUBLIC
}

\author{
${ }^{1}$ Richter Josef, ${ }^{2}$ Vetvicka Vaclav, ${ }^{1}$ Kral Vlastimil, ${ }^{3}$ Svozil Vladimir, \\ ${ }^{1}$ Pohorska Jitka, ${ }^{1}$ Stiborova Ivana, ${ }^{1}$ Sturcova Hana and ${ }^{1}$ Rajnohova Dobiasova Lucie \\ ${ }^{1}$ Zdravotní ústav se sídlem v Ústí nad Labem, Czech Republic \\ ${ }^{2}$ Department of Pathology, University of Louisville, Louisville, KY, USA \\ ${ }^{3}$ Sanatorium Edel, Zlaté Hory, Czech Republic
}

Received 2014-08-06; Revised 2014-09-06; Accepted 2014-12-24

\begin{abstract}
In our paper we decided to evaluate the hypothesis about the relation between living conditions, infection with Helicobacter pylori and development of allergic problems. Two groups of children, one from the Roma population and one from the majority population, were chosen for this study. Comparing the levels of total IgE and specific IgE antibodies, IgA and IgG Helicobacter pylori antibodies in both populations, we found significant differences in all tested aspects. We conclude that changes in lifestyle together with changes in improvements in living conditions and reduction of risk factors can significantly influence the health conditions of thepopulation and overall quality of life.
\end{abstract}

Keywords: Helicobacter, Immunity, Infection, Roma, Allergy

\section{INTRODUCTION}

The incidence of allergic atopy and asthma severely increased in the last decades, but the reasons for this occurrence are still unclear. Among suggested associations is exposure to tobacco smoke (Arnold et al., 2011; Hancox et al., 2004; Laszewicz et al., 2014; Moayyedi et al., 2002; Roesler et al., 2014; Wang et al., 2012), quality of indoor conditions (Laszewicz et al., 2014), quality of environment (Hancox et al., 2004; Krumbiegel et al., 2000; Roesler et al., 2014; Rothenbacher et al., 1998; Vasar et al., 2011; Wang et al., 2012; Wex et al., 2010), genetic and race influences $(10,17,22,26,29,32)$, social-economic effects and education (Amedei et al., 2010; Bode et al., 2002; Chen and Blaser, 2008; Hancox et al., 2004; Laszewicz et al., 2014; Leal et al., 2008), exposure to allergens from domestic animals (Amedei et al., 2010) and lately the exposure to nanoparticles from car exhausts, mainly with diesel engines (Amedei et al., 2010). Another theory speculates about the possibility that the use of antibiotics given either therapeutically or in small amounts in food influences composition of the microbiome and triggers the allergies (Arnold et al., 2011, Blaser 2012; Fu 2014; Holster et al., 2012). On the other hand, there are known mechanisms leading to reduction of the risk of allergic diseases. Among them, effects of infections such as Bordetella pertussis, flu, enteroviruses, hepatitis A or Toxoplasma gondi were found (Amedei et al., 2010; Reibman et al., 2008). The most studied effects seem to be persisting infection with Helicobacter Pylori (HP) (Amedei et al., 2010; Arnold et al., 2011; 2012; Blaser, 2012; Bode et al., 2002; Bridge and Merrell, 2013; Chen and Blaser, 2008; Karimi et al., 2013; Kato and Sherman, 2005; Krumbiegel et al., 2000; Oertli and Muller, 2012; Pacifico et al., 2014; Perez-Perez et al., 2003; Reibman et al., 2008; Rothenbacher et al., 1998). HP survives in the human gastrointestinal tract and, in addition to clinical manifestations such as lymphoma, adenocarcinoma or gastric ulcers, it can cause iron and vitamin B12 deficiencies, idiopathic thrombocytopenic purpura or growth retardation in children (Amedei et al., 2010). HP colonizes stomach Corresponding Author: Vaclav Vetvicka, Department of Pathology, University of Louisville, 511 S. Floyd, Louisville, KY 40202, USA 
at an early age, causes medical problems in adulthood and persists for the entire life (Amedei et al., 2010).

In 1989, Strachan hypothesized that persisting exposure to infectious agents and long-term living in unhygienic conditions can "educate" the immune system and therefore leads to the defense against development of allergic diseases. A balance between Th1 and Th2 lymphocyte population is the main foundation of this hypothesis. It is possible that HP infection resulting in predominant activation of Th1 cells with subsequent production of IFN- $\gamma$, IL-12, IL-18, IL-23 and TNF- $\alpha$ leads to the inhibition of allergic problems regulated by Th2 (Amedei et al., 2010). Another possible mechanism might be the ability of HP infection to induce regulatory $\mathrm{T}$ lymphocytes. This might explain why HP-negative patients are more predisposed to allergic diseases. We hypothesize that higher exposure to microorganisms at a young age results in achieving an immune system balance and a subsequently lower appearance of health problems resulting from immune imbalance.

We decided to use the Roma pediatric population as a model for our evaluation of the effects of high exposure to HP from early childhood. This group of children differs from the majority population in the Czech Republic in lifestyle and nutrition habits and is characterized by a high concentration of persons sharing one room (an average of 4 persons per room). In addition, this population suffers from high exposure to tobacco smoke (both passive and active), as $80 \%$ of Roma women smoke during pregnancy. When compared to the majority population, the Roma population significantly differs in morbidity rates (Hajioff and McKee, 2000; Nesvadbova et al., 2000). Scabies prevalence reached 265 cases per 10,000 in Roma population compared to just 7.7 in majority population. Similarly, there are large differences in the incidence of viral hepatitis A (58.3:1), shigellosis (57:1), or salmonellosis (144:38). A variety of socio-economic factors such as lifestyle, low level of education, bad nutrition and other factors clearly results in a shorter lifespan of the Roma population, which is app. 10-15 years shorter when compared to majority population. A low interest in their own health observed among Roma people also adds to the short lifespan (Nesvadbova et al., 2000). These facts led us to this study.

\section{MATERIALS AND METHODS}

\subsection{Protocol}

From a total of 353 children aged 7-14 years, we tested 152 Roma children (mean age 10.01), 98 males with a mean age of 10.4 years and 54 females with a mean age of 9.7 years). The control group consisted of 211 aged 7-11 years children from the majority population (a mean age of 10.4; 107 males and 104 females of the same mean age). All children were from the same region of North-West Bohemia, an area with extreme environmental pollution caused by heavy concentration of surface mines, chemical industry and coal-powered power stations. In addition, this area suffers from a low level of socioeconomic conditions, the lowest level of education and the highest unemployment in the Czech Republic. The study was approved by the Ethics committees of the Public Health Institute. This study was performed in agreement with the Helsinki Declaration (revised version 2000.09.01) and in full compliance with the rules for clinical testing in the Czech Republic. Parental consent was given in all cases.

We used blood drawn for comprehensive evaluation, the antibody response to Helicobacter pylori and general levels of total and specific IgE were evaluated for our study.

\subsection{Tests}

Specific IgE was tested by high-affinity fluorescent enzyme immunoassay (CAP FEIA, Pharmacia Upjohn, Peapack, NJ, USA). Levels of IgE higher than 0.35 $\mathrm{kU} / \mathrm{L}$ were considered positive. In addition, we measured specific antibodies against inhalation allergens CAP Phadiotop (complex of inhalation allergens), against cat dander (e1), dog dander (e5), k82 (Hevea brasiliensis) and food allergens (mixture of egg white, milk, fish [cod], wheat, peanuts and soya beans). The total IgE was evaluated using Immulite 2000 analyzer using standards and diagnostics recommended by the manufacturer.

IgG and IgA antibodies to $H$. pylori were measured by an Enzyme-Linked Immunosorbent Assay (ELISA). Commercial sets (Meridian Diagnostics) were used according to the manufacturer's recommendations. Concentration of antibodies above $20 \mathrm{U} / \mathrm{mL}$ was treated as positive result of $H$ pylori infection (Laszewicz et al., 2014).

\subsection{Statistical Analysis}

Statistical significance was evaluated by a paired $t$ test using GraphPad Prism 5.04 software (GraphPad Software, USA). A mean and standard deviation were evaluated after determination of composition of standard values. For evaluation of prevalence differences, we used Fisher's exact test. 


\section{RESULTS}

Anti-HP antibodies of the IgG class were found in $64 \%$ of Roma children and only in $20.4 \%$ of control population. Similar findings were found in case of antiHP IgA antibodies-51.3\% in Roma population Vs $17.4 \%$ in the control group. Figure 1 summarized the appearance of antibodies in individual groups. It shows the differences in various isotypes of immunoglobulins between the tested groups. Our findings of differences in specific antibodies are statistically highly significant $(\mathrm{p}<0.0001)$. Positivity of specific IgE antibodies (CAP Phadiatop) was detected in $13.2 \%$ of the tested Roma population with no significant differences based on sex (13.3\% in males, $13.0 \%$ in females). The findings of specific antibodies in the control group were also significant $(p<0.001)$, with $43.9 \%$ of positive males and $36.5 \%$ of positive females (40.2\% total). The prevalence rates of specific IgE and anti-HP antibodies are summarized in Fig. 2. The total levels of IgE were higher than $100 \mathrm{Ul} / \mathrm{L}$ in $26.3 \%$ of the Roma subjects and in $34.6 \%$ of the controls.
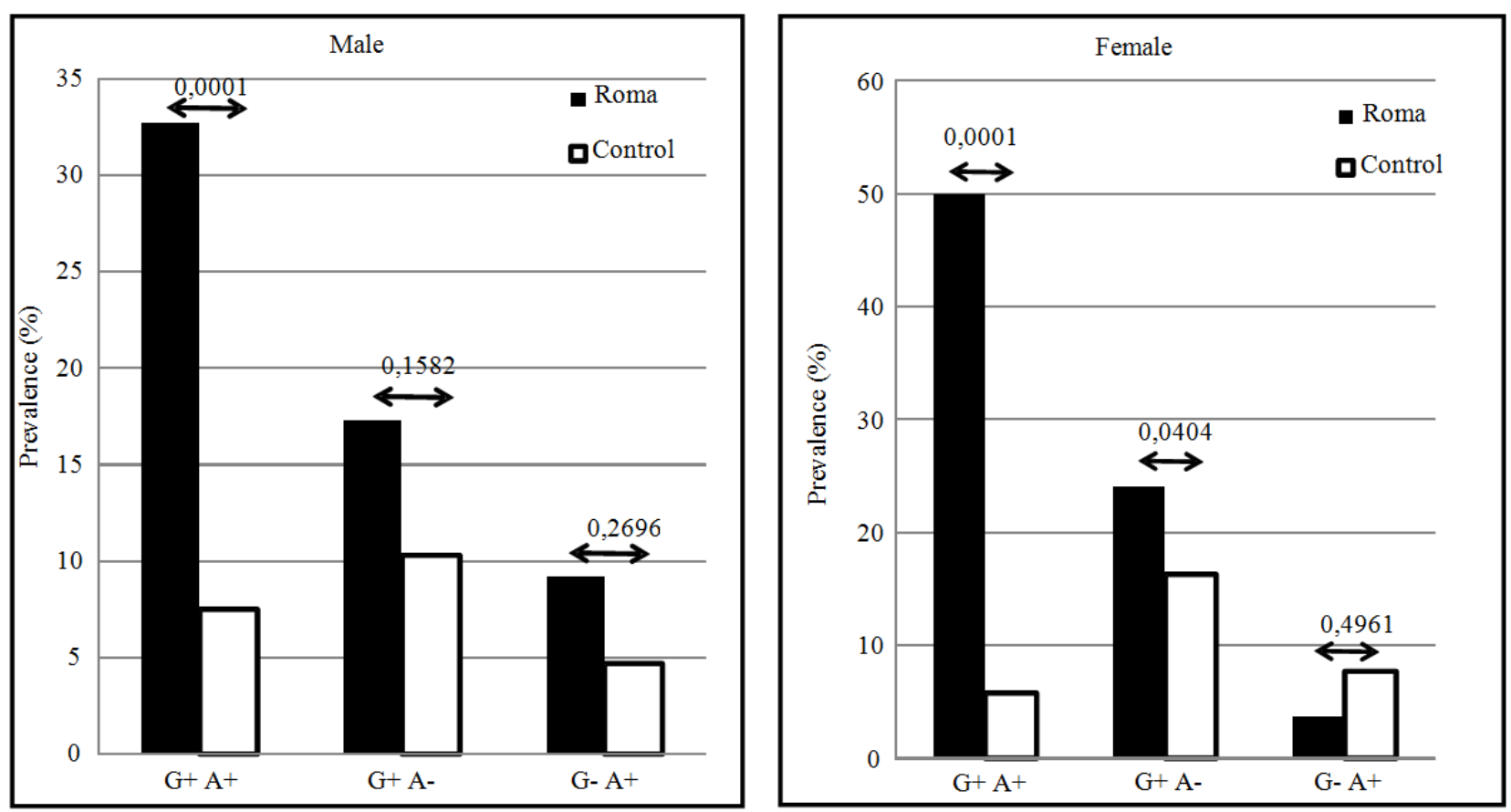

\begin{tabular}{|c|c|c|c|c|c|c|c}
\hline Male & G+ A+ & G+ A- & G- A+ & Female & G+ A+ & G+ A- & G- A+ \\
\hline Gypsies & 32,7 & 17,3 & 9,2 & Gypsies & 50 & 24,1 & 3,7 \\
\hline Control & 7,5 & 10,3 & 4,7 & Control & 5,8 & 16,3 & 7,7 \\
\hline Fisher exact test & 0,0001 & 0,1582 & 0,2696 & Fisher exact test & 0,0001 & 0,0404 & 0,4961 \\
\hline RR & 0,7279 & 0,9212 & 0,9527 & RR & 0,5306 & 0,8191 & 1,043 \\
\hline CI 95\% & $0,6277-$ & $0,8244-$ & $0,9932-$ & & & $0,4047-$ & $0,6707-$ \\
& 0,8440 & 1,030 & 1,028 & CI $95 \%$ & 0,6958 & 1,000 & $0,9666-$ \\
& & & & & & & \\
\hline
\end{tabular}

Fig. 1. The types of IgG and IgA Helicobacter antibody combinations found in the serum of children from the Roma and majority population in the Czech Republic (RR-relative risk, CI-95\% confidence interval). 


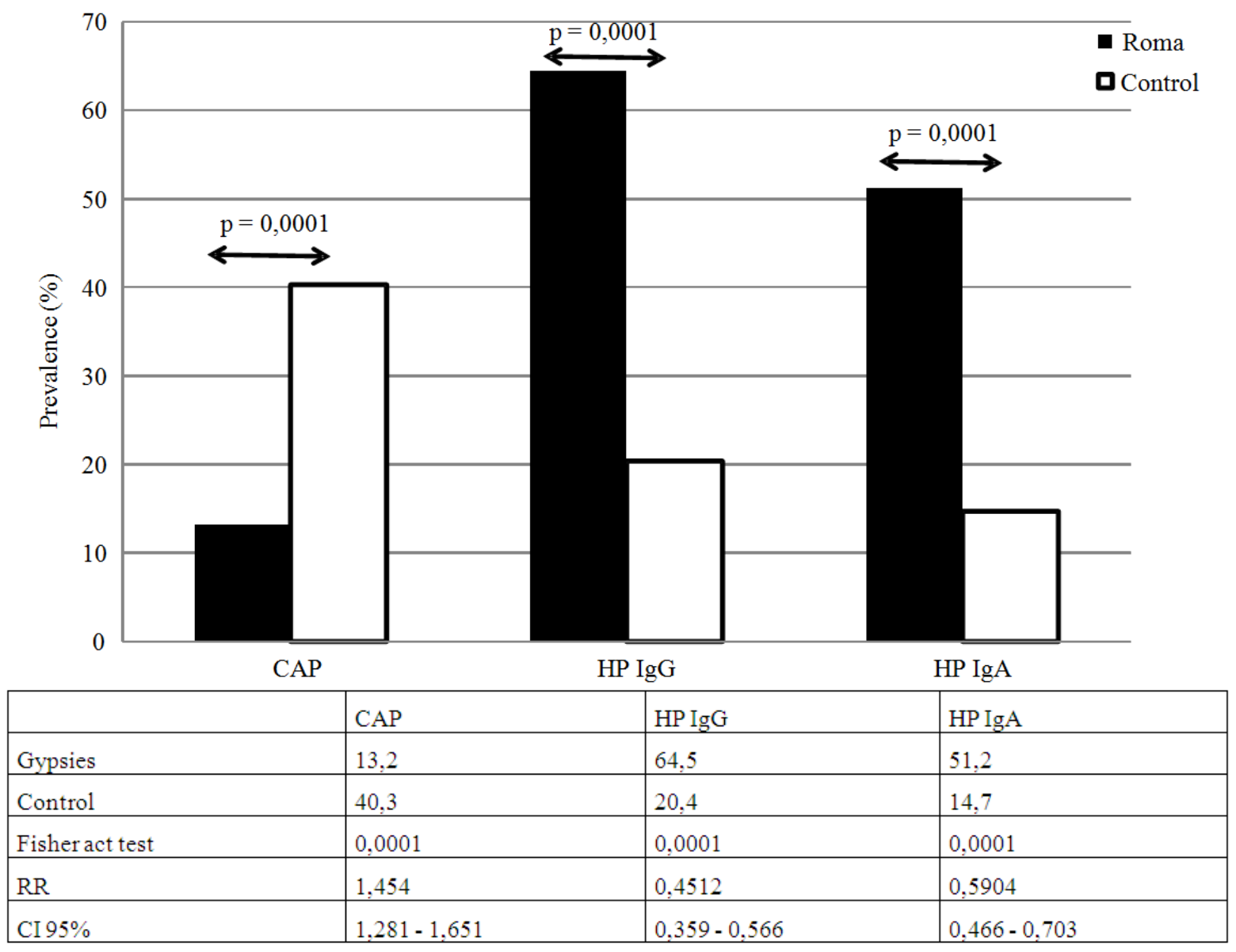

Fig. 2. Seroprevalence of Helicobacter pylori infection $\operatorname{IgG}$ and $\operatorname{IgA}$ antibody level (above $20 \mathrm{IU} / \mathrm{mL}$ ) and specific $\operatorname{IgE}$ antibodies in the Roma chikdren and controls (male and female). (RR-relative risk, CI-95\% confidence interval)

\section{DISCUSSION}

The study focused on the prevalence of $\operatorname{IgA}$ and $\operatorname{IgG}$ antibody response against HP. We used commercial kits employing ELISA and guaranteeing high specificity and sensitivity, which allowed us to compare the infection prevalence in different tested groups, varying in regions and even countries (Gosciniak, 1997; Sunnerstam et al., 1999). In our groups of children, we found significant differences in anti-HP antibody response. The group of Roma children was $65.8 \%$ positive, whereas the group made up of children from the majority population was only $26.1 \%$ positive. The level of positivity significantly differs among individual countries. Our findings in the control group are slightly higher than those published by German authors, ranging from 4.8 to 14.6\% (Bode et al., 2002; Krumbiegel et al., 2000; Rothenbacher et al., 1998; Wex et al., 2010). On the other hand, a group of Turkish children living in Germany has much higher positivity of 37.9 to $44.8 \%$ (Bode et al., 2002; Rothenbacher et al., 1998). In Poland, 32\% of positive cases among children were reported, whereas the Dutch population reached only $9 \%$ positivity (Holster et al., 2012). The average level of positivity in the US studies is $27.3 \%$ (Perez-Perez et al., 2003), but the majority population of New York has lower positivity of $16.8 \%$ (Reibman et al., 2008). It was suggested that the positivity in children in developed countries was app. 16 to $20 \%$, whereas in developing countries this can reach 80 to $90 \%$ of tested children (Kariya et al., 2014). It is clear that these findings are significantly influenced by lifestyle, nutrition, social conditions, quality of living, education level of parents and other factors (Amedei et al., 2010; Gold et al., 2001; Hancox et al., 2004; Krumbiegel et al., 2000; Laszewicz et al., 2014; Mitchell et al., 2003; 
Moayyedi et al., 2002; Perez-Perez et al., 2003; Reibman et al., 2008; Rothenbacher et al., 1998; Vasar et al., 2011). The Roma population originates in Northern India and has lived in Europe for more than 1,000 years (Hajioff and McKee, 2000). In the last 100 years, they have migrated throughout Europe, forming closed communities with persisting inadequate lifestyle, low education and substandard level of hygiene, leading to low interest in their own health. The low standards of living results in high risk of infections, manifested from an early age (Hajioff and McKee, 2000). Close communication of individuals subsequently leads to early and frequent infection with HP. In addition, infectious diseases (namely hepatitis A and E) can help to modulate the immune system. Reports suggesting that HP infections can help to reduce risk of allergic diseases and asthma (Amedei et al., 2010; Arnold et al., 2001; 2012; Chen and Blaser, 2008; Holster et al., 2012; Karimi et al., 2013; Oertli and Muller, 2012; Reibman et al., 2008; Wang et al., 2012) led us to our study evaluating groups of children originating in the majority and Roma populations with the aim to find possible differences in specific and general antibody response to inhaled and food allergens. Our findings seem to confirm the hypothesis of a positive role of HP infection in the development of allergic diseases. Persisting HP infection can also be connected with additional extragastric problems such as low iron anemia, growth problems and other health disorders (Kariya et al., 2014; Kato and Sherman, 2005; Pacifico et al., 2014). It is possible to speculate that higher exposure to chemical agents and antibiotics (compared to the situation 100 years ago) results in reduction of HP infection and subsequent increase of allergic diseases and asthma (Blaser, 2012), which further supports the hypothesis of HP infection-induced protection against allergies. Current important changes in microbiome quality and composition results in generation and higher frequency of additional diseases (Blaser, 2012; Gold et al., 2001). The hypothesis of possible restoration of the gastrointestinal microbiome either via reduction of continuous exposure to chemical pollutant or by prevention of allergic diseases (e.g., by anti-HP vaccination) is becoming more and more relevant (Annesi-Maesano et al., 2012; Bode et al., 2002). The benefits of using HP Neutrophil Activating Protein not only for diagnostic and therapeutic purposes, but also for prevention by vaccination has been experimentally proved (Fu, 2014). We conclude that changes in lifestyle together with changes in improvements in living conditions and reduction of risk factors can significantly increase the health conditions of the population and their overall quality of life.

\section{ADDITIONAL INFORMATION}

\subsection{Author's Contributions}

All authors equally contributed in this work.

\subsection{Ethics}

This article is original and contains unpublished material. The corresponding author confirms that all of the other authors have read and approved the manuscript and no ethical issues involved.

\section{REFERENCES}

Amedei, A., G. Codolo, G. Del Prete, M. Bernand and M D'Elios, 2010. The effect of Helicobacter pylori on asthma and allergy. J. Asthma Allergy, 3: 139147. DOI: $10.2147 /$ JAA.S8971

Annesi-Maesano, I., M. Hulin, F. Lavaud, C. Raherison and C. Kopferschmitt et al., 2012. Poor air quality in classrooms related to asthma and rhinitis in primary schoolchildren of the French 6 cities study. Thorax, 67: 682-688. DOI: 10.1136/thoraxjnl-2011-200391

Arnold, I.C., I. Hitzler and A. Müller, 2012. The immunomodulatory properties of Helicobacter pylori confer protection against allergic and chronic inflammatory disordes. Frontiers Cell. Inform. Microbiol., 2: 1-11. DOI: 10.3389/fcimb.2012.00010

Arnold, I.C., N. Dehzad, S. Reuter, H. Martin and B. Becher et al., 2011. Helicobacter pylori infection prevents allergic asthma in mouse models through the induction of regulatory T cells. J. Clin. Invest., 121: 3088-3093. DOI: 10.1172/JCI45041

Blaser, M.J., 2012. Equilibria of humans and our indigenous microbiota affecting asthma. Proc. Am. Thror. Soc., 9: 69-71. DOI: 10.1513/pats.201108-048MS

Bode, G., I. Piechotowski, D. Rothenbacher and H. Brenner, 2002. Helicobacter pylori-Specific immune responses of children: Implications for future vaccination strategy. Clin. Diag. Lab. Immunol., 9: 1126-1128. DOI: 10.1128/CDLI.9.5.1126-1128.2002

Bridge, R.D. and D.S. Merrell, 2013. Polymorphism in the Helicobacter pyloriCagA and VacA toxins and disease. Gut Microb., 4: 101-117. DOI: 10.4161/gmic. 23797

Chen, Y. and J. Blaser, 2008. Helicobacter pylori colonization is inversely associated with childhood asthma. J. Infect Dis., 15: 553-560. DOI: $10.1086 / 590158$ 
$\mathrm{Fu}$, H.W., 2014. Helicobacter pylori neutrophilactivating protein: From molecular pathogenesis to clinical applications. World J. Gastroenterol., 20: 5294-5301. DOI: 10.3748/wjg.v20.i18.5294

Gold, B.D., L.J. Doorn and J. Guarner, 2001. Genotypic, clinical and demographic characteristics of children infected with Helicobacter pylori. J. Clin. Microbiol., 39: 1348-1352. DOI: 10.1128/JCM.39.4.1348-1352.2001

Gosciniak, G., 1997. IgG and IgA antibodies in Helicobacter pylori infections. Zbl. Bakt., 286: 494502. DOI: 10.1016/S0934-8840(97)80052-7

Hajioff, S. and M. McKee, 2000. The health of the Roma people: A review of the publisher literature. J. Epidemiol. Comm. Health, 54: 864-896. DOI: 10.1136/jech.54.11.864

Hancox, R.R., B.J. Milne and D.R. Taylor, 2004. Relationship between socioeconomic status and asthma: A longitudinal cohort study. Thorax, 59: 376-380. DOI: 10.1136/thx.2003.010363

Holster, I.L., A.M.J. Vila, D. Caudri, C.M. den Hoed and G.I. Perez-Perez et al., 2012. The impact of Helicobacter pylori on atopic disorders in childhood. Helicobacter, 17: 232-237. DOI: 10.1111/j.1523-5378.2012.00934.x

Karimi, A., K. Fakhimi-Derakhshan, F. Imanzadeh, M. Rezaei and Z. Cavoshzadeh et al., 2013. Helicobacter pylori infection and pediatric asthma. Iran. J. Microbiol., 5: 132-135. PMID: 23825730

Kariya, S., M. Okano and K. Nishizaki, 2014. An association between Helicobacter pylori and upper respiratory disease: Fact or fiction? World J. Gastroenterol., 20: 1470-1484. DOI: 10.3748/wjg.v20.i6.1470

Kato, S. and P.M. Sherman, 2005. What is new related to Helicobacter pylori infection in children and teenagers? Arch. Pediat. Adolesc. Med., 159: 415421. DOI: 10.1001/archpedi.159.5.415

Krumbiegel, P., O. Herbarth, G. Fritz, U. Schlink and F.J. Gutsmuths et al., 2000. Helicobacter pylori prevalence in Leipzig's 1998 school entries: Metodology and first results. Int. J. Hyg. Environ. Health, 203: 11-16. DOI: 10.1078/S14384639(04)70002-4

Laszewicz, W., F. Iwańczak and B. Iwańczak, 2014. Seroprevalence of Helicobacter pylori infection in Polish children and adults depending on socioeconomic status and living conditions. Adv. Med. Sci., 59: 147-150. DOI: 10.1016/j.advms.2014.01.003
Leal, Y.A., L.L. Flores, L.B. García-Cortés, R. CedilliRivera and J. Torres, 2008. Antibody-based detection tests for the diagnosis of Helicobacter pylori infection in children: A meta-anylysis. PLoS ONE, 3: e3751e3751. DOI: 10.1371/journal.pone.0003751

Mitchell, A., T.M.J. Silva, L.J. Barrett, A.A. Lima and R.L. Guerrant, 2003. Age-specific Helicobacter pyloriseropositivity rates of children in an impoverished urban area of Northeast Brazil. J. Clin. Microbiol., 41: 1326-1328. DOI: 10.1128/JCM.41.3.1326-1328.2003

Moayyedi, P., A.T.R. Axon, R. Feltbower, S. Duffetta and W. Crocombec et al., 2002. Relation of adult lifestyle and socioeconomic factors to the prevalence of Helicobacter pylori infection. Int. J. Epideomiol., 31: 624-631. DOI: 10.1093/ije/31.3.624

Nesvadbova, L., J. Rutsch, A. Kroupa and S. Sojka, 2000. The state of health of the Romany population in the Czech Republic. Cent. Eur. J. Publ. Health, 8: 141-149. PMID: 10965436

Oertli, M. and A. Müller, 2012. Helicobacter pylori targets dendritic cells to induce immune tolerance, promote persistence and confer protection against allergic asthma. Gut Microb., 3: 566-571. DOI: $10.4161 /$ gmic. 21750

Pacifico, L., J.F. Osborn, V. Tromba, S. Romaggioli and S. Bascetta et al., 2014. Heliobacter pylori infection and extragastric disorders in children: A critical update. World J. Gastroenterol., 20: 1379-1401. DOI: $10.3748 /$ wjg.v20.i6.1379

Perez-Perez, G.I., R.B. Sack, R. Reid, M. Santosham and J. Croll et al., 2003. Transient and persistent Helicobacter pylori colonization in native American children. J. Clin. Microbiol., 41: 2401-2407. DOI: 10.1128/JCM.41.6.2401-2407.2003

Reibman, J., M. Marmor, J. Filner, M.E. FernandezBeros and L. Rogers et al., 2008. Asthma is inversely associated with Helicobacter pylori status in an urban population. PLoS ONE, 3: e4060-e4060. DOI: 10.1371/journal.pone.0004060

Roesler, B.M., E.M.A. Rabelo-Goncalves and J.M.R. Zeitune, 2014. Virulence factors of Helicobacter pylori: A review. Clin. Med. Insights: Gastroenterol, 7: 9-17. DOI: 10.4137/CGast.S13760

Rothenbacher, D., G. Bode, G. Berg, R. Gommel and T. Gonser et al., 1998. Prevalence and determinant sofHelicobacter pylori infection in preschool children: A population-based study from Germany. Int. J. Epidemiol., 27: 135-141. DOI: 10.1093/ije/27.1.135 
Sunnerstam, B., T. Kjerstadius, L. Jansson, J. Giesecke and M. Bergstrom et al., 1999. Detection of Helicobacter pylori antibodies in a pediatric population: Comparison of three commercially available serological tests and one in-house enzyme immunoassay. J. Clin. Microbiol., 37: 3328-3331. PMID: 10488200

Vasar, M., K. Julge, M. Kivivare and K. Otter, 2011. Regional differences in diagnosing asthma and other allergic diseases in Estonian schoolchildren. Medicina, 47: 661-666. PMID: 22370465
Wang, Y., Y. Bi, L. Zhang and C. Wang, 2012. Is Helicobacter pylori infection associated with asthma risk? A meta-analysis based on 770 cases and 785 controls. Int. J. Med. Sci., 9: 603-610. DOI: 10.7150/ijms. 4970

Wex, T., M. Venerito, J. Kreutzer, T. Götze and A. Kandulski et al., 2010. Serological prevalence of Helicobacter pylori infection in Saxony-anhalt, Germany. Clin. Vaccine Imunol., 18: 2109-2112. DOI: 10.1128/CVI.05308-11 